\title{
Editorial
}

\section{Thirty Years of VCOT Publication and Still Evolving}

Kenneth A. Johnson ${ }^{1}$

1 Sydney School of Veterinary Science, University of Sydney, Sydney, Australia

Vet Comp Orthop Traumatol 2017;30:v.

This final issue of Veterinary and Comparative Orthopaedics and Traumatology for 2017 represents another milestone, with thirty years of uninterrupted publication of the Journal. In the first twenty years we published four issues a year, then six issues a year in the recent ten years. That's a total of 140 issues, or roughly 1,500 papers published over the life of the journal. Starting out in 1988 under the guidance of our founding Editor in Chief, the late Geoff Sumner Smith, our journal has been steadfastly nurtured, supported and published by Schattauer in Stuttgart Germany. During this time we have seen many changes and improvements such as electronic processing of manuscript, open access publishing, and listing by the indexing services.

The publication of this issue of VCOT brings yet another change. I want to extend a very warm welcome to Dr Elinor Switzer who has been appointed as the new Managing Editor of the Journal. Dr Switzer is a veterinarian and a member of Schattauer's staff who has already had a long association with VCOT, so she is very familiar with our Journal. The first thing to notice in this issue is a change in page layout from three columns to two columns. There are some other minor changes, such as format of reference citation, as well. We will soon be revising our 'Instructions to Authors' on the VCOT Web site page, so that authors of new manuscripts have clear guidelines for formatting their manuscript prior to submission.

Apart from these changes in lay-

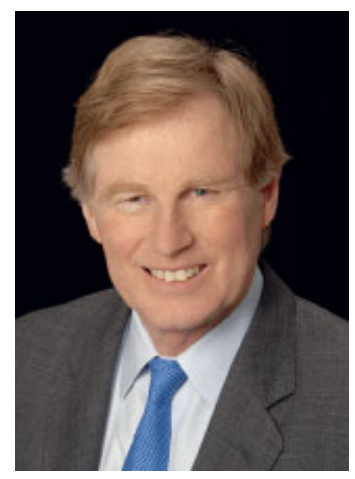

Kenneth A. Johnson out, I am not planning any alterations to our processes for peer review and evaluation of papers, or our relationship with the various societies for whom we are proud to serve as their official journal.

Our guest editorial has been contributed by a member of our review board, Dr Stephen Page whose specialty is veterinary pharmacology and therapeutics. I am very grateful to Dr Page for providing his thoughtful commentary that you are sure to find to be a good read.

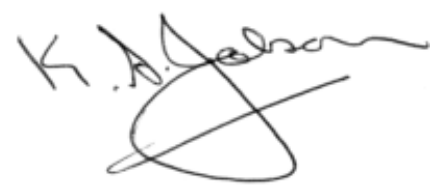

Kenneth A. Johnson

Editor-in-Chief

Sydney, Australia 